\title{
Vulnerabilidade ao stress, estratégias de coping e autoeficácia em professores portugueses
}

\author{
Margarida Pocinho \\ Universidade da Madeira \\ Maria Regina Capelo \\ Secretaria Regional da Educação e Cultura
}

\section{Resumo}

Neste trabalho, apresentamos uma investigação realizada com professores, no qual se procura determinar a vulnerabilidade ao stress; identificar as principais fontes de stress; estabelecer as principais estratégias de coping; analisar se as estratégias deste condicionam a presença de stress laboral; e reconhecer se a autoeficácia percebida é preditora desse tipo de stress. Trata-se duma investigação por questionário, do tipo correlacional, e a amostra é constituída por 54 professores do Ensino Básico público português. As respostas ao Questionário sociodemográfico e profissional; ao Questionário de Vulnerabilidade ao Stress - 23QVS (Serra, 2000); ao Questionário de Stress nos Professores - QSP (Gomes et al., 2006; Gomes, 2007); ao Coping Job Scale - CJS de Latack (adaptação de Jesus \&t Pereira, 1994); e à Escala de Avaliação de Autoeficácia Geral (Ribeiro, 1995) revelam que 20,4\% dos docentes são vulneráveis ao stress; os comportamentos inadequados/indisciplina dos alunos são as principais fontes de stress; as estratégias de controlo são as mais utilizadas pelos participantes para enfrentar o stress, seguidas das de escape e das de gestão de sintomas. Os professores não vulneráveis ao stress utilizam principalmente estratégias de controlo e apresentam níveis mais elevados de eficácia perante a adversidade, bem como de iniciativa e persistência em relação aos professores vulneráveis ao stress.

\section{Palavras-chave}

Stress - Coping - Autoeficácia - Professores. 


\title{
Vulnerability to stress, coping strategies and self-efficiency among Portuguese teachers
}

\author{
Margarida Pocinho \\ Universidade da Madeira \\ Maria Regina Capelo \\ Secretaria Regional da Educação e Cultura
}

\begin{abstract}
In this work we present a research carried out on teachers to determine their vulnerability to stress, to identify the main sources of stress, to recognize teachers' main coping strategies, to analyze whether such strategies condition the presence of stress at work, and to establish whether the self-efficiency perceived can be used to predict work stress. This is a correlational questionnaire-based research performed on a 54teacher sample from Portugal's public basic education schools. The answers to the Social, Demographic and Professional Questionnaire, to the Stress Vulnerability Questionnaire - 23QVS (Serra, 2000), to the Teacher Stress Questionnaire - QSP (Gomes et al., 2006; Gomes, 2007), to the Coping Job Scale - CJS (Latack, adapted by Jesus and Pereira, 1994) and to the General Self-efficiency Assessment Scale (Ribeiro, 1995) reveal that $20.4 \%$ of teachers are vulnerable to stress. The study shows that the main stress sources are found in students' lack of discipline or improper behaviour, and that control strategies are the most common to deal with stress, followed by escape strategies and symptom management. Teachers not vulnerable to stress use mainly control strategies and they display higher efficiency levels under adversity, as well as more initiative and perseverance than the teachers that are vulnerable to stress.
\end{abstract}

\section{Keywords}

Stress - Coping - Self-efficiency - Teachers.

Contact:

Maria Regina T. Ferreira Capelo

Estr da Regional 225, 15, Arco da

Calheta

9370-042 - Madeira - Portugal

E-mail: m.regina.capelo@gmail.com 


\section{Stress}

$\mathrm{Na}$ sociedade actual, o stress converteuse num fenómeno relevante e tem vindo a condicionar o comportamento e o desenvolvimento pessoal (Gomes, 2006; Guillén Gestoso, 2005). Proveniente do latim, esse termo existe na língua inglesa desde o século XV. Esse conceito foi se alterando ao longo dos tempos, sendo que no século XIX se referia à força externa, pressão ou tensão a que são submetidas pessoas ou objectos, resistindo aos seus impactos (Guillén Gestoso, 2005).

No início do século XX, o termo stress passou a ser utilizado na área da saúde e, actualmente, invade o discurso quotidiano, adquirindo uma importância relevante na vida das pessoas. Hans Selye (1956), nos anos 1950, introduziu o conceito de stress na sua obra intitulada $A$ syndrome produced by diverse nocuous agents.

Também Lazarus e Folkman (1984) contribuíram para o estudo do stress. Para os referidos autores, este consiste no confronto permanente entre o indivíduo e o seu mundo exterior, onde a avaliação do sujeito determina se essa relação excede, ou não, as suas capacidades e se, eventualmente, coloca em causa o seu bem-estar.

Na opinião de Vaz Serra (2005), "ninguém está livre de stress" (p. 29). Nesse sentido, clarifica que um indivíduo sente-se em stress quando está perante um acontecimento que para si é significativo e o qual não controla e/ou que as exigências impostas por este ultrapassam as suas aptidões e os recursos pessoais e sociais para enfrentá-lo. Assim, como o ser humano enfrenta as circunstâncias indutoras do stress de forma diferenciada, a vulnerabilidade ao stress também não é uniforme.

Nesse âmbito, o modelo de stress proposto por Vaz Serra (1999) procura apresentar uma síntese clara e actual do processo de stress e de coping.

O coping, relacionado com o modo como as pessoas lidam com as situações adversas indutoras de stress, tem sido objecto de estudo no quadro das organizações pela importância que assume no campo do trabalho.

Vaz Serra (1999) considera que o stress só se verifica perante situações de tensão desencadeadoras de experiências stressantes, sendo que tais situações podem ser acontecimentos subjectivos - como pensamentos, imagens ou sensações internas - ou objectivos como acontecimentos relevantes da vida ou acontecimentos incomodativos do dia a dia. Desse modo, a avaliação dos acontecimentos por parte do indivíduo dá-lhe a percepção de ter ou não recursos suficientes para lidar com a problemática, pois se as exigências colocadas pela situação forem superiores aos recursos disponíveis no indivíduo, então este sente que não tem capacidade de controlo e pode entrar em stress.

Ainda de acordo com Vaz Serra (1999), o stress não tem de ser encarado sempre como nocivo. Na sua perspectiva,

[...] em situações intermédias o stress pode ser útil porque se torna propulsivo, ou seja, constitui uma fonte de impulso que faz com que o indivíduo tome decisões e resolva problemas, ajudando-o a melhorar o seu funcionamento e as suas aptidões. 0 stress, neste sentido, traz algum sabor à vida e pode constituir-se um incentivo de realização profissional e pessoal. (p. 16)

Essa ideia sugere-nos que a existência de algum stress tem uma função protectora e adaptadora, conduzindo o sujeito para a acção.

Em conformidade com Jesus (2002; 2005), o stress pode constituir-se como um factor de desenvolvimento e promotor de sentimentos de eficácia pessoal (eustress), mas se o sujeito não for bem-sucedido ou se não possuir as competências adequadas para lidar com as exigências, surgem os sintomas de mal-estar (distress).

A esse respeito, Jesus (2002; 2005), na sistematização que apresenta sobre o processo de desenvolvimento das situações de eustress e 
de distress, realça que uma situação percepcionada como difícil e exigente pelo sujeito vai desencadear nele resistência e estratégias de coping. Se a tentativa de lidar com a situação for bem-sucedida, o indivíduo depara-se com eustress, de tal forma que quando se confrontar, no futuro, com uma situação idêntica, apresentar-se-á mais confiante e terá maior probabilidade de solucionar o problema de forma eficaz.

$\mathrm{Na}$ verdade, esse fenómeno assume contornos significativos quando associado ao mundo do trabalho, pois as exigências colocadas aos trabalhadores pelas mudanças aceleradas impostas pela vida moderna, de que nos fala Toffler (1970), são geradoras de tensões e de desorientações, podendo simultânea e consequentemente constituir fontes de desgaste físico e psicológico para estes. Essa questão é particularmente evidente quando aplicada aos professores, uma vez que a docência, segundo Kyriacou e Sutcliffe (1978), é apontada como uma actividade extremamente exigente, geradora de níveis de stress superiores a outras profissões nas quais esse fenómeno é habitualmente observado.

Assim, à medida que o stress se tem vindo a converter num fenómeno relevante e reconhecido a nível social, tem crescido também a pesquisa, tomando em consideração os efeitos para a saúde, para o bem-estar individual e com especial relevância no âmbito laboral. Aliás, estudos conduzidos um pouco por todo o mundo salientam que a classe docente inserese nas profissões que apresentam níveis mais elevados de stress. No início da década de 80 do século XX, a Organização Internacional do Trabalho (01T, 1981) denunciava a gravidade da situação ao referi-la como uma das principais causas de abandono da profissão docente, a qual considerava como uma prática profissional de risco de esgotamento físico e mental.

De acordo com vários estudos realizados na Inglaterra, os níveis de stress subjectivo percepcionado pelos professores parece ter duplicado ao longo de 25 anos, isto é, dos 20\% referidos por Kyriacou e Sutcliffe (1978), passaram para valores na ordem dos $40 \%$ (Capel, 1991) e 44\% (Cockburn, 1996).

Algumas pesquisas recentes efectuadas em Portugal também evidenciam que esse fenómeno parece atingir com particular incidência os professores portugueses (Pinto; Lima; Silva, 2003; Gomes, 2006). Contudo, compete a cada pessoa a capacidade de aprender a lidar com todas essas contradições.

\section{Coping}

0 interesse pelas diversas formas de adaptação das pessoas a circunstâncias adversas, assim como pelos seus esforços para lidar com situações indutoras de stress, tem-se constituído em objecto de estudo por meio do constructo chamado coping.

0 termo coping pode ter o significado de lidar com, enfrentar, encarar, ultrapassar, fazer face, dar resposta a, reagir a ou adaptarse a circunstâncias adversas. Esse conceito, segundo Mota e Matos (2006), emerge no século XIX associado à ideia de "defesa" amplamente desenvolvida pela psicanálise, sendo que os estudos conduzidos na época apontavam para uma associação com a psicopatologia e dependiam da avaliação dos processos inconscientes. Na perspectiva dos referidos autores, a partir da década de 60 do século XX, o termo coping afasta-se do conceito de "defesa". As estratégias conscientes de reacção às situações de stress começam a ser conceptualizadas como respostas de coping.

Durante os anos 70 e 80 do século XX, as investigações realizadas deixam de estar centradas exclusivamente no mundo interno da pessoa, passando a considerar também factores contextuais. Assim sendo, perante as adversidades, o coping comporta diversas formas de lidar com as transacções que ocorrem entre o indivíduo e o meio (Lazarus; Folkman, 1984).

Folkman et al. (1986) definem o coping como "os esforços cognitivos e comportamentais desenvolvidos pela pessoa, para gerir (reduzir, minimizar, dominar ou tolerar) as exigências 
internas e externas das transacções pessoais que são avaliadas como excedendo os recursos da pessoa [...]” (p. 572). lsto é, os esforços que cada um faz para lidar com o stress.

Assim, o coping, entendido como a capacidade de a pessoa lidar com o stress, é um fenómeno adaptativo que contribui para a sua sobrevivência e para um adequado desempenho das suas actividades em diversas vertentes da vida.

Em 1984, Latack propõe três categorias de coping: (1) acção, focada na situação de stress; (2) reavaliação, centrada nas cognições sobre a situação; e (3) gestão de sintomas, focalizada nos sintomas de stress ou estados psicofisiológicos. Note-se que as duas primeiras categorias estão associadas a situações específicas, enquanto a terceira é mais geral. Lazarus e Folkman (1984) acrescentam também que as estratégias proactivas correspondem às estratégias de coping focado na resolução de problemas e que as estratégias de evitamento correspondem às de coping focadas na emoção.

Jesus e Pereira (1994) afirmam, posteriormente, que Latack (1986) conceptualiza as categorias de coping do seguinte modo: (1) controlo, que consiste em acções e reavaliações cognitivas proactivas; (2) escape, que se baseia em acções e cognições que sugerem evitamento; e ainda (3) gestão de sintomas, alicerçadas em estratégias para gerir os sintomas ligados ao stress profissional em geral.

É de referir que Latack (1986), ao constatar a escassez de instrumentos destinados à avaliação das estratégias de coping, apoiando-se na distinção entre as três categorias de coping, procedeu à elaboração de uma escala constituída por 52 itens que avaliava a frequência com que um indivíduo utilizava determinadas estratégias.

Jesus e Pereira (1994), num estudo realizado em Portugal sobre as estratégias de coping que são utilizadas pelos professores para lidarem com o mal-estar ocupacional, aplicaram uma tradução do Coping Job Scale de Latack (1986), o que se revelou de extrema importância.

Esses autores verificaram que os docentes inquiridos utilizavam significativamente mais estratégias de controlo ou confronto, seguindose as de escape ou evitamento e, por último, as de gestão de sintomas.

Em conformidade com a escala supracitada, os 52 itens que a constituem encontram-se aglutinados em três dimensões, a saber:

- Estratégias de controlo ou confronto discutir a situação com o supervisor; tentar ser muito organizado para gerir as situações; falar com outras pessoas envolvidas; tentar ver a situação como uma oportunidade para aprender e desenvolver novas competências; colocar atenção redobrada no planeamento e no horário, para não cometer erros; tentar pensar em si como um vencedor; dizer a si próprio que pode, provavelmente, trabalhar as coisas à sua maneira; dedicar mais tempo e energia no trabalho; tentar obter o apoio de mais pessoas envolvidas na situação; pensar nas mudanças que podem ser feitas naquela situação; tentar trabalhar mais depressa e mais eficazmente; decidir o que deve ser feito e explicar isso às pessoas envolvidas; dar o seu melhor; pedir ajuda das pessoas que têm o poder de fazer algo por si; procurar conselhos das pessoas que podem ajudar; trabalhar para a mudança de políticas que estão na base da situação; e empenhar-se mais no trabalho e durante mais horas.

- Estratégias de escape ou evitamento evitar encontrar-se na situação; dizer a si próprio que o tempo toma conta desta situação; tentar estar fora de situações deste tipo; lembrar-se que o trabalho não é tudo; antecipar as consequências para preparar-se para o pior; delegar o trabalho nos outros; separar-se tanto quanto possível das pessoas que criaram a situação; tentar não ficar interessado sobre a situação; fazer o melhor para sair gracioso da situação; aceitar a situação porque não há nada que possa fazer para a modificar; e estabelecer as próprias prioridades com base naquilo que gosta de fazer. 
- Estratégias de gestão de sintomas - dormir; beber um pouco de licor, cerveja ou vinho; beber mais quantidade de bebidas alcoólicas do que deve; tomar tranquilizantes, sedativos ou outros medicamentos; praticar desporto; praticar meditação transcendental; usar o treino de "biofeedback"; fazer relaxamento; procurar a companhia de amigos; procurar a companhia de família; comer; ver televisão; assistir a acontecimentos desportivos, culturais ou comunitários; afastar os problemas da família ou dos amigos; adoptar passatempos, como sejam actividades de leitura; fazer compras/gastar dinheiro; trabalhar menos tempo; mudar o estado físico, arranjando o cabelo, fazendo massagens, sauna ou actividade sexual; fazer uma viagem para outra cidade; "sonhar" durante o trabalho; procurar ajuda profissional ou aconselhamento; rezar; queixar-se a outras pessoas; e fumar. (Jesus; Pereira, 1994, p. 265-266)

No referido estudo, Jesus e Pereira (1994) concluíram que é impossível efectuar uma avaliação plena da eficácia de qualquer estratégia de coping dada a sua ligação a factores situacionais e de personalidade. Nesse sentido, alertam para a necessidade de realização de estudos que possibilitem a análise das estratégias de coping em situações específicas de mal-estar docente.

No entanto, apesar de considerar importante a investigação sobre os factores de mal-estar docente, posteriormente, Jesus (2005) advoga que parece ser preferivel uma abordagem mais optimista que evidencie os aspectos mais positivos da profissão docente e, em termos de investigação, tentar identificar as condições necessárias para o bem-estar e realização profissional dos professores.

Ainda que as estratégias de coping tenham vindo a ser consideradas numa perspectiva de promoção da saúde e da qualidade de vida dos trabalhadores, Salanova, Bresó e Schaufeli (2005) acrescentam que estas são influenciadas pela autoeficácia.

\section{Autoeficácia}

A noção de autoeficácia emerge, na década de 70 do século $X X$, plasmada na teoria sociocognitiva de Bandura (1997) e é definida como as crenças do indivíduo nas suas capacidades para organizar e executar as acções desejadas para produzir resultados esperados. Isso significa que as crenças de autoeficácia se referem aos juízos que cada pessoa faz acerca das suas capacidades para empreender uma tarefa.

Bandura (1997) advoga que as pessoas possuem um sistema interno, nomeadamente crenças de autoeficácia, que lhes permite exercer controlo sobre as suas próprias acções, condutas e pensamentos, sendo esse sistema de fundamental influência para que o indivíduo atinja metas e execute com sucesso as tarefas a que se propõe. Se as pessoas acreditam que não têm poder para produzir resultados, não tentam que eles aconteçam. Logo, podemos depreender que, se o indivíduo se julga capaz e confia nas suas habilidades de execução de uma tarefa específica, esta autopercepção contribuirá para o êxito do seu desempenho.

De facto, segundo Ribeiro (1995) e Salanova, Grau e Martínez (2006), as expectativas de eficácia poderão, eventualmente, afectar a própria tentativa de enfrentar as situações e a escolha dos locais de acção.

Nesse pressuposto, a percepção de autoeficácia pode ter efeitos diversificados na forma como nos comportamos, nos nossos padrões de pensamento e nos aspectos emocionais; determina, igualmente, a quantidade de esforço que o indivíduo vai dispor e durante quanto tempo persistirá ante os desafios (Ribeiro, 1995).

Depois da Teoria Social Cognitiva de Bandura (1997), surgiram outros estudos que procuram demonstrar que a autoeficácia exerce um papel moderador perante as fontes de stress laboral.

Concretamente, Grau, Salanova, e Peiró (2001) sustentam que a autoeficácia modera as relações entre as fontes de stress e as suas 
consequências, no sentido em que baixos níveis de autoeficácia estão associados a maiores níveis de stress vivido. Também Salanova, Grau e Martínez (2006) defendem que, a níveis superiores de autoeficácia, associam-se níveis baixos de mal-estar psicológico.

Nessa perspectiva, os indivíduos com níveis altos de autoeficácia, que possuem confiança nas suas habilidades para responder aos estímulos do meio, podem exercer controlo sobre eles e tendem a usar estratégias de coping activas em situações de sobrecarga laboral.

0 exercício da profissão docente, tal como acontece noutras profissões de serviços sociais, em que o contacto com as pessoas é permanente, pode percepcionar-se muito relevante e cheia de desafios, mas por outro lado e em simultâneo, pode revelar-se cheia de medos e ameaças, tanto a nível profissional como pessoal. Isso acontece porque, em conformidade com García-Renedo et al. (2004), o professor é o próprio instrumento de trabalho, mediador em interacções de ensino/aprendizagem dentro de um contexto que actualmente apresenta maiores exigências.

Enfim, pelas razões expostas, pensamos que o sentido de autoeficácia do professor exerce influência sobre o seu desempenho.

0 objectivo deste estudo é analisar os efeitos da autoeficácia e das estratégias de coping em relação ao stress nos professores. Logo, esta investigação procura ser mais um contributo para a compreensão da problemática nesse grupo profissional e desenvolve-se em torno dos seguintes objectivos específicos: (1) determinar a vulnerabilidade dos professores ao stress; (2) identificar as principais fontes de stress; (3) estabelecer as principais estratégias de coping; (4) analisar se as estratégias de coping condicionam a presença de stress laboral; e (5) reconhecer se a autoeficácia é preditora do stress laboral.

\section{Método}

Realizamos uma pesquisa de carácter descritivo, transversal e amostral. Aplicamos questionários numa amostra de professores portugueses para avaliar a vulnerabilidade ao stress, identificar fontes, estratégias de coping e a importância da autoeficácia. Esta investigação é descritiva e correlacional porque analisa a influência da autoeficácia e das estratégias de coping em relação ao stress e estuda a relação entre esses factores.

\section{Participantes}

Participaram neste estudo 54 professores portugueses em exercício na Região Autónoma da Madeira, sendo 66,7\% mulheres (36 sujeitos) e 33,3\% homens (18 sujeitos). A diferença de idade nos sujeitos oscila entre um mínimo de 26 e um máximo de 52 anos. No que diz respeito ao estado civil, temos 37\% solteiros/divorciados/ separados e $63 \%$ casados ou a viver maritalmente. A graduação dos professores por habilitações académicas distribui-se pela licenciatura com 90,7\%; mestrado com 7,4\%; e bacharelato com 1,9\%. Da sua distribuição por nível de ensino, consta o seguinte: no Ensino Básico, $1^{\circ}$ Ciclo, 72,2\% (39 sujeitos); $2^{\circ}$ Ciclo, 9,3\% (5 sujeitos); $3^{\circ}$ Ciclo, 13\% (7 sujeitos); e no Ensino Secundário, 5,6\% (3 sujeitos). A antiguidade na carreira oscila entre 1 e 31 anos.

A taxa de retorno e de adesão foi de $90 \%$, sendo que os dados recolhidos provêm de uma amostra de conveniência formada na base do voluntariado dos participantes.

\section{Instrumentos}

No processo de recolha de dados para avaliar as diversas variáveis, tivemos em consideração o significado teórico destas e procedemos à respectiva recolha de informação sobre quais os instrumentos necessários para o estudo. Nesse decurso, pudemos verificar a disponibilidade de versões já validadas para a população portuguesa e para a totalidade das dimensões consideradas. Então, entregamos um envelope aos participantes com os seguintes instrumentos: 
- Uma folha introdutória, com uma breve apresentação sobre a natureza e objectivos do estudo, na qual se procurava motivar o professor, realçando a importância da sua participação, e um questionário sociodemográfico e profissional que, para além de avaliar as variáveis demográficas como o género, a idade e o estado civil, procurou recolher dados relativos à formação académica e ao nível de ensino ministrado.

- Questionário de Vulnerabilidade ao Stress 23 QVS -, desenvolvida por Vaz Serra (2000), que permite avaliar a vulnerabilidade que um indivíduo tem ao stress. Essa escala está construída de maneira que a cotação final quanto mais elevada é, mais se relaciona com vulnerabilidade ao stress (pontuação igual ou acima de 43 traduz vulnerabilidade ao stress). É de referir que quanto mais elevado é o valor da 23 QVS, menor tendência existe para uma atitude de confronto activo dos problemas e maior tendência tem o indivíduo de os sentir como fora do seu próprio controlo.

- Questionário de Stress nos Professores QSP -, que foi adaptado por Gomes et al. (2006) e Gomes (2007) a partir dos trabalhos realizados por Cruz e Freitas (1988), Cruz e Mesquita (1988) e Kyriacou e Sutcliffe (1978) e contém 36 itens divididos por seis factores, a saber: Comportamentos inadequados/indisciplina dos alunos; Pressões de tempo/excesso de trabalho; Diferentes capacidades e motivações dos alunos; Estatuto da carreira docente; Trabalho burocrático/administrativo; Políticas disciplinares inadequadas. Os valores totais de cada subescala são calculados por meio da soma dos itens de cada dimensão, dividindose depois o valor encontrado pelo número total de itens que a constituem. Nesse sentido, os resultados de cada um dos factores apresentados pode variar entre um mínimo de zero e um máximo de quatro, representando os valores máximos de níveis mais elevados de stress.

- Coping Job Scale - CJS - de Latack (1986), na adaptação portuguesa de Jesus e Pereira
(1994), que se destina à avaliação das estratégias de coping e compreende 52 itens, sendo 17 de controlo, 11 de escape e os restantes 24 de gestão de sintomas. É de realçar que as estratégias de controlo consistem em acções e reavaliações cognitivas que são proactivas; as de escape, em acções e cognições que sugerem evitamento; e, por último, as de gestão de sintomas, que se baseiam em estratégias para gerir os sintomas ligados ao stress profissional em geral. Não pretendemos, contudo, avaliar a eficácia das estratégias de coping para a resolução de problemas, mas sim avaliar o grau em que o sujeito utiliza determinadas estratégias. - Finalmente, Escala de Avaliação da Autoeficácia Geral - Como Eu Sou, de Ribeiro (1995), assenta numa adaptação da SelfEfficacy Scale de Sherer et al. (1982), que constitui uma medida de autoeficácia geral. A escala engloba três dimensões: iniciação e persistência; eficácia perante a adversidade; e eficácia social. No entanto, Ribeiro (1995) assevera que se discute as limitações e vantagens dessa escala de autoeficácia tal como é concebida por Bandura.

\section{Procedimentos}

0 questionário, que englobava os instrumentos atrás referidos, foi distribuído no mês de abril de 2008 para 60 docentes portugueses, tendo sido recebidos e considerados como válidos, para efeitos do presente estudo, 54 questionários, representando uma taxa de retorno e adesão de 90\%. A informação recolhida foi posteriormente organizada e analisada de acordo com os objectivos do estudo.

\section{Análise estatística}

0 tratamento e a análise estatística dos dados obtidos foram processados no programa informático Statistical Package for Social Science - SPSS -, versão 16.0 para Windows.

Em primeiro lugar, fizemos um estudo descritivo das variáveis sociodemográficas e pro- 
fissionais da amostra, cujos principais resultados já estão enunciados no ponto respeitante à amostra deste trabalho. Encontrámos as percentagens para as variáveis nominais género, idade, estado civil, habilitações académicas e nível de ensino.

Para a análise das diferentes variáveis em apreço, recorremos aos testes de qui-quadrado, ao teste t-Student e aos coeficientes de correlação de Pearson.

\section{Resultados}

Num primeiro olhar sobre os nossos dados, pudemos observar que 20,4\% (11) dos professores incluídos na nossa amostra são indicados como vulneráveis ao stress e que, a maioria, 79,6\% (43), não se revelou vulneráveis.

Comparando os valores expressos na Tabela 1, podemos observar diferença tendencial em relação ao género, pois $22,2 \%$ das mulheres são vulneráveis ao stress enquanto os homens revelam uma menor prevalência, com o valor de 16,7\%. No entanto, os dados não permitem concluir que existam diferenças significativas entre homens e mulheres, porque o valor de significância é superior a 0,05.
Da mesma forma, não é possível afirmar que seja o grupo dos professores solteiros ou que vivem sós os que apresentam maior vulnerabilidade ao stress. Nesse caso, observamos 20\% e 20,6\% respectivamente vulneráveis ao stress, logo não é possível afirmar que o estado civil esteja associado a uma maior prevalência de vulnerabilidade e ao stress.

Os resultados apresentados na Tabela 2 indicam que 100\% dos professores vulneráveis ao stress possuem licenciatura como grau académico e leccionam no $1^{\circ}$ Ciclo do Ensino Básico.

Os dados da Tabela 3 mostram que, considerando a totalidade da amostra, os comportamentos inadequados e a indisciplina dos alunos são, de facto, as fontes de stress que apresentam um score mais alto. De seguida, com 59,06\%, aparecem as pressões de tempo e o excesso de trabalho, sendo que o trabalho burocrático é a fonte menos responsável pelo stress percebido pelos professores.

Considerando a totalidade da amostra, verificamos que as estratégias de coping mais utilizadas pelos professores para enfrentarem o stress são as estratégias de controlo com score médio de 64,24\%. Com menor importância,

Tabela 1: Influência das variáveis sociodemográficas na vulnerabilidade ao stress.

\begin{tabular}{|c|l|c|c|c|c|}
\hline \multicolumn{2}{|c|}{} & \multicolumn{3}{c|}{ Não vulnerável ao stress } & \multicolumn{2}{c|}{ Vulnerável ao stress } \\
\cline { 3 - 6 } \multicolumn{2}{|c|}{} & $n$ & $\%$ & $n$ & $\%$ \\
\hline \multirow{2}{*}{$\begin{array}{c}\text { Género } \\
\left(\bullet^{2}=0,228 ; \text { gl=1;sig=0,633) }\right.\end{array}$} & Feminino & 28 & $77,8 \%$ & 8 & $22,2 \%$ \\
\cline { 2 - 6 } & Masculino & 15 & $83,3 \%$ & 3 & $16,7 \%$ \\
\hline \multirow{2}{*}{$\begin{array}{c}\text { Estado Civil } \\
\left(\bullet^{2}=0,003 ; \text { gl=1;sig=0,959) }\right.\end{array}$} & Solteiro/Divorciado/Separado & 16 & $80,0 \%$ & 4 & $20,0 \%$ \\
\cline { 2 - 6 } & Casado/União de facto & 27 & $79,4 \%$ & 7 & $20,6 \%$ \\
\hline
\end{tabular}

Tabela 2: Influência das variáveis profissionais na vulnerabilidade ao stress.

\begin{tabular}{|c|c|c|c|c|c|}
\hline & \multicolumn{2}{|c|}{ Não vulnerável ao stresse } & \multicolumn{2}{|c|}{ Vulnerável ao stresse } \\
\hline & & $\mathrm{n}$ & $\%$ & $\mathrm{n}$ & $\%$ \\
\hline \multirow{3}{*}{$\begin{array}{c}\text { Grau acadêmico } \\
\left(\bullet^{2}=1,41 ; \text { gl }=2 ; \text { sig }=0,494\right)\end{array}$} & Bacharelato & 1 & $100,0 \%$ & 0 & $0 \%$ \\
\hline & Licenciatura & 38 & $77,6 \%$ & 11 & $22,4 \%$ \\
\hline & Mestrado & 4 & $100,0 \%$ & 0 & $0 \%$ \\
\hline \multirow{4}{*}{$\begin{array}{c}\text { Nivel de ensino } \\
\left(\bullet^{2}=5,313 ; \text { gl }=3 ; \text { sig }=0,15\right)\end{array}$} & $1^{\circ}$ Ciclo & 28 & $71,8 \%$ & 11 & $28,2 \%$ \\
\hline & $2^{\circ}$ Ciclo & 5 & $100,0 \%$ & 0 & $0 \%$ \\
\hline & $3^{\circ}$ Ciclo & 7 & $100,0 \%$ & 0 & $0 \%$ \\
\hline & Secundário & 3 & $100,0 \%$ & 0 & $0 \%$ \\
\hline
\end{tabular}


surgem as estratégias de escape com 45,71\%; e finalmente as de gestão de sintomas, com score médio de 28,7\%. Note-se que os resultados obtidos nesse domínio vão de encontro aos obtidos no estudo realizado por Jesus e Pereira (1994) e Quirino (2007) (Tabela 4).

Na Tabela 5, apresentamos os 52 itens, antecedidos pelo respectivo número que o posiciona na CJS, de Latack, por ordem decrescente das médias obtidas. Assim, podemos precisar que as estratégias de coping mais utilizadas pelos professores são, principalmente, as de controlo, sendo "Dar o meu melhor para fazer aquilo que penso ser esperado de mim" $(M=4,1)$ a mais utilizada; seguindo-se "Tentar ser muito organizado para poder gerir as situações" $(M=4,0)$; e "Colocar atenção redobrada no planeamento e no horário, para não cometer erros" $(M=3,8)$.

Da Tabela 6, depreendemos que existem correlações significativamente diferentes de zero. Nesse sentido, destacamos:

- A gestão de sintomas( ${ }^{*}$ ) está correlacionada com a vulnerabilidade ao stress, porque o coeficiente de correlação é significativo. No entanto, embora baixo, o facto de ser positivo indica que os professores mais vulneráveis ao stress também utilizam mais a estratégia gestão de sintomas.

- A gestão de sintomas apresenta-se correlacionada com a estratégia de escape $\left.{ }^{* *}\right)$. Isso

Tabela 3: Principais fontes de stresse nos professores.

\begin{tabular}{|l|c|}
\hline & $\bar{x} \pm S$ \\
\hline Comportamentos inadequados/indisciplina dos alunos & $68,72 \pm 19,78$ \\
\hline Pressões do tempo/excesso de trabalho & $59,06 \pm 18,61$ \\
\hline Diferentes capacidades e motivações dos alunos & $54,01 \pm 19,34$ \\
\hline Estatuto da carreira docente & $56,93 \pm 22,90$ \\
\hline Trabalho burocrático/administrativo & $48,15 \pm 28,02$ \\
\hline Políticas disciplinares inadequadas & $56,40 \pm 18,51$ \\
\hline
\end{tabular}

Tabela 4: Estratégias de coping utilizadas pelos professores.

\begin{tabular}{|l|c|c|}
\hline & $\mathbf{n}$ & $\bar{x} \pm S$ \\
\hline Estratégias de Controlo & 54 & $64,24 \pm 11,25$ \\
\hline Estratégias de Escape & 54 & $45,71 \pm 12,48$ \\
\hline Estratégias de Gestão de Sintomas & 54 & $28,70 \pm 10,77$ \\
\hline
\end{tabular}

denota que quanto maior é o score do escape, maior é também o score da gestão de sintomas.

Na Tabela 7, podemos observar que os professores vulneráveis ao stress apresentam menos controlo, mais evasão e gestão de sintomas do que os não vulneráveis. Entretanto, essas diferenças não têm significado estatístico, porque em todos os testes a significância foi superior a 0,05. 0 afastamento maior entre professores vulneráveis e não vulneráveis ao stress é de 5,22\%. Assim, de acordo com os resultados apurados, quer se trate de um professor vulnerável ou não, as estratégias de coping utilizadas para lidar com o stress são idênticas nos dois grupos.

Os parâmetros assinalados na Tabela 8 revelam que os professores participantes nesta amostra são eficazes e persistentes perante a adversidade, pois a pontuação média é extremamente elevada, ultrapassando os 91\%.

Optamos por não incluir a dimensão eficácia social porque, em concordância com Ribeiro (1995), esta revelou níveis de fiabilidade muito baixos, pois cálculo da consistência interna efectuado com base no alpha de Cronbach denunciou um coeficiente de 0,443.

Na situação expressa na Tabela 9, as diferenças que têm significado estatístico ocorrem ao nível da iniciativa e persistência, sendo que os professores não vulneráveis ao stress são os que apresentam maior pontuação média, com uma diferença de 15,42\% relativamente aos vulneráveis ao stress. Quanto à eficácia perante a adversidade, os professores não vulneráveis ao stress são mais eficazes, apresentando uma média de $97,7 \%$, enquanto na amostra de professores vulneráveis, a média é 89,7\%.

A Tabela 10 mostra que os professores que têm um score elevado ao nível da iniciativa e persistência (**) também apresentam um score elevado na variável eficácia perante a adversidade $(*)$. Por outro lado, podemos apreciar que, à percepção de maior eficácia perante a adversidade, correspondem mais estratégias de controlo. Por sua vez, a estratégia gestão de sintomas está 
Tabela 5: Estratégias de coping utilizadas pelos professores.

\begin{tabular}{|c|c|c|}
\hline Estratégia & Descrição & Média \\
\hline Controlo & $\begin{array}{l}\text { 13. Dar o meu melhor para fazer aquilo que penso ser esperado } \\
\text { de mim }\end{array}$ & 4,1 \\
\hline Controlo & 2. Tentar ser muito organizado para poder gerir as situações & 4,0 \\
\hline Controlo & $\begin{array}{l}\text { 5. Colocar atenção redobrada no planeamento e no horário para } \\
\text { não cometer erros }\end{array}$ & 3,8 \\
\hline Controlo & $\begin{array}{l}\text { 4. Tentar ver a situação como uma oportunidade para aprender e } \\
\text { desenvolver novas competências }\end{array}$ & 3,8 \\
\hline Controlo & 8. Dedicar mais tempo e energia a fazer o meu trabalho & 3,7 \\
\hline Controlo & 11. Tentar trabalhar mais depressa e eficazmente & 3,7 \\
\hline Controlo & $\begin{array}{l}\text { 12. Decidir o que deve ser feito e explicar isso às pessoas que se } \\
\text { encontram envolvidas }\end{array}$ & 3,7 \\
\hline Controlo & 10. Pensar nas mudanças que podem ser feitas na situação & 3,7 \\
\hline Controlo & 3. Falar com outras pessoas envolvidas & 3,6 \\
\hline Controlo & $\begin{array}{l}\text { 17. Empenhar-me mais no trabalho e trabalhar durante mais } \\
\text { horas }\end{array}$ & 3,5 \\
\hline Escape & 26. Fazer o meu melhor para sair graciosamente da situação & 3,5 \\
\hline Escape & $\begin{array}{l}\text { 28. Estabelecer as minhas próprias prioridades com base no que } \\
\text { gosto de fazer }\end{array}$ & 3,5 \\
\hline Controlo & $\begin{array}{l}\text { 14. Pedir a ajuda das pessoas que têm o poder de fazer alguma } \\
\text { coisa por mim }\end{array}$ & 3,4 \\
\hline Gestão de sintomas & 38. Procurar a companhia da família & 3,4 \\
\hline Controlo & $\begin{array}{l}\text { 7. Dizer a mim próprio que posso provavelmente trabalhar as } \\
\text { coisas à minha maneira }\end{array}$ & 3,4 \\
\hline Controlo & 9. Tentar obter o apoio de mais pessoas envolvidas na situação & 3,4 \\
\hline Controlo & $\begin{array}{l}\text { 6. Tentar pensar em mim como um vencedor, como alguém que } \\
\text { chega sempre de cabeça erguida }\end{array}$ & 3,4 \\
\hline Controlo & $\begin{array}{l}\text { 15. Procurar conselhos de pessoas que se encontram fora da } \\
\text { situação, mas que me podem ajudar a pensar como fazer o que é } \\
\text { esperado de mim }\end{array}$ & 3,2 \\
\hline Gestão de sintomas & 37. Procurar a companhia dos amigos & 3,2 \\
\hline Controlo & $\begin{array}{l}\text { 16. Trabalhar para a mudança de políticas que estão na base da } \\
\text { situação }\end{array}$ & 3,2 \\
\hline Escape & $\begin{array}{l}\text { 22. Antecipar as consequências negativas para estar preparado } \\
\text { para o pior }\end{array}$ & 3,1 \\
\hline Escape & 18. Evitar encontrar-me na situação se puder & 3,1 \\
\hline Controlo & 1. Discutir a situação com o meu supervisor & 3,1 \\
\hline Gestão de sintomas & 42. Afastar os problemas da família ou dos amigos & 3,0 \\
\hline Escape & $\begin{array}{l}\text { 24. Separar-me tanto quanto possível das pessoas que criaram } \\
\text { esta situação }\end{array}$ & 2,9 \\
\hline Gestão de sintomas & 43. Adoptar passatempos, como sejam actividades de leitura & 2,9 \\
\hline Escape & 20. Tentar estar fora de situações deste tipo & 2,8 \\
\hline Escape & 21. Lembrar-me que o trabalho não é tudo & 2,8 \\
\hline Gestão de sintomas & 40. Ver televisão & 2,7 \\
\hline Gestão de sintomas & 33. Praticar desporto & 2,7 \\
\hline Escape & 25. Tentar não ficar interessado sobre a situação & 2,6 \\
\hline Escape & $\begin{array}{l}\text { 27. Aceitar esta situação porque não há nada que eu possa fazer } \\
\text { para a modificar }\end{array}$ & 2,5 \\
\hline Gestão de sintomas & $\begin{array}{l}\text { 41. Assistir a acontecimentos desportivos, culturais ou } \\
\text { comunitários }\end{array}$ & 2,5 \\
\hline Escape & $\begin{array}{l}\text { 19. Dizer a mim próprio que o tempo toma conta deste tipo de } \\
\text { situações }\end{array}$ & 2,4 \\
\hline Gestão de sintomas & $\begin{array}{l}\text { 46. Mudar o estado físico, arranjando o cabelo, fazendo } \\
\text { massagens, sauna ou actividade sexual }\end{array}$ & 2,3 \\
\hline Gestão de sintomas & 44. Fazer compras/ Gastar dinheiro & 2,2 \\
\hline Gestão de sintomas & 39. Comer & 2,2 \\
\hline Gestão de sintomas & 49. Procurar ajuda profissional ou aconselhamento & 2,2 \\
\hline Gestão de sintomas & 51. Queixar-me a outras pessoas & 2,1 \\
\hline Gestão de sintomas & 45. Trabalhar menos tempo & 2,1 \\
\hline Gestão de sintomas & 29. Dormir & 2,0 \\
\hline Gestão de sintomas & 47. Fazer uma viagem para outra cidade & 2,0 \\
\hline Gestão de sintomas & 50. Rezar & 2,0 \\
\hline Gestão de sintomas & 36. Fazer relaxamento & 1,9 \\
\hline Escape & 23. Delegar o trabalho a outros & 1,9 \\
\hline Gestão de sintomas & 48. "Sonhar" durante as horas de trabalho & 1,6 \\
\hline Gestão de sintomas & 30. Beber um pouco de licor, cerveja ou vinho & 1,4 \\
\hline Gestão de sintomas & 35. Usar o treino de "biofeedback" & 1,4 \\
\hline Gestão de sintomas & 52. Fumar & 1,4 \\
\hline Gestão de sintomas & 32. Tomar tranquilizantes, sedativos ou outros medicamentos & 1,4 \\
\hline Gestão de sintomas & 34. Praticar meditação transcendental & 1,4 \\
\hline Gestão de sintomas & 31. Beber mais quantidade de bebidas alcoólicas que o devido & 1,2 \\
\hline
\end{tabular}


Tabela 6: Vulnerabilidade ao stress e estratégias de coping.

\begin{tabular}{|c|c|c|c|c|c|}
\hline & & Vulnerabilidade ao stresse & Controlo & Escape & Gestão de sintomas \\
\hline \multirow[t]{2}{*}{ Vulnerabilidade ao stresse } & $\mathrm{R}$ & 1,000 &,- 089 & ,022 &, $273^{*}$ \\
\hline & Sig & & ,524 & ,874 & ,046 \\
\hline \multirow[t]{2}{*}{ Controlo } & $\mathrm{R}$ &,- 089 & 1,000 & , 106 &,- 212 \\
\hline & Sig &, 524 & & ,446 &, 124 \\
\hline \multirow[t]{2}{*}{ Escape } & $\mathrm{R}$ & ,022 & , 106 & 1,000 &, $360^{* *}$ \\
\hline & Sig & 874 & ,446 & & ,007 \\
\hline \multirow[t]{3}{*}{ Gestão de sintomas } & $\mathrm{R}$ & $273^{\circ}$ &,- 212 &, $360^{* *}$ & 1,000 \\
\hline & Sig & ,046 &, 124 & ,007 & \\
\hline & $\mathrm{N}$ & 54 & 54 & 54 & 54,000 \\
\hline
\end{tabular}

${ }^{*} \operatorname{sig}<0,05 \quad{ }^{* *} \operatorname{sig}<0,01$

Tabela 7: Estratégias de coping e vulnerabilidade ao stresse.

\begin{tabular}{|l|c|c|c|c|c|}
\hline \multirow{2}{*}{} & Não vulnerável ao stresse & Vulnerável ao stresse & \multicolumn{3}{|c|}{ Teste t-Student } \\
\cline { 2 - 6 } & $\bar{x} \pm S$ & $\bar{x} \pm S$ & $\mathrm{t}$ & sig & Diferença das médias \\
\hline Controlo & $64,5 \pm 8,2$ & $63,4 \pm 19,7$ &, 286 &, 776 & 1,09750 \\
\hline Escape & $45,6 \pm 13,1$ & $46,1 \pm 10,1$ &,- 108 &, 914 &,- 46127 \\
\hline Gestão de sintomas & $27, \pm 10,2$ & $32,9 \pm 12,5$ & $-1,450$ &, 153 & $-5,21934$ \\
\hline
\end{tabular}

Tabela 8: Autoeficácia geral.

\begin{tabular}{|l|c|c|}
\hline & $\mathrm{N}$ & $\bar{x} \pm S$ \\
\hline Iniciativa e persistência & 54 & $91,83 \pm 12,26$ \\
\hline Eficácia perante a adversidade & 54 & $96,05 \pm 13,35$ \\
\hline
\end{tabular}

Tabela 9: Vulnerabilidade ao stress e autoeficácia geral.

\begin{tabular}{|l|c|c|c|c|c|}
\hline & Não vulnerável ao stress & Vulnerável ao stress & \multirow{2}{*}{$\mathrm{t}$} & \multirow{2}{*}{ sig } & Diferença das médias \\
\cline { 2 - 4 } & $\bar{x} \pm S$ & $\bar{x} \pm S$ & & & \\
\hline Iniciativa e persistência & $95,0 \pm 10,5$ & $79,5 \pm 11,0$ & 4,291 &, 000 & 15,42225 \\
\hline Eficácia perante a adversidade & $97,7 \pm 13,0$ & $89,7 \pm 13,3$ & 1,806 &, 077 & 7,97745 \\
\hline
\end{tabular}

Tabela 10: Estratégias de coping e a autoeficácia geral.

\begin{tabular}{|c|c|c|c|c|}
\hline \multirow{2}{*}{ Iniciativa e persistência } & & Controlo & Escape & Gestão de sintomas \\
\cline { 2 - 5 } & $\mathrm{R}$ &, 201 &,- 094 &,$- 372^{* *}$ \\
\hline \multirow{2}{*}{ Eficácia perante a adversidade } &, 145 &, 500 &, 006 \\
\hline & $\mathrm{R}$ &, 302 &,- 136 &,- 230 \\
\hline & $\mathrm{Sig}$. &, 026 &, 326 &, 094 \\
\hline & $\mathrm{N}$ & 54 & 54 & 54 \\
\hline
\end{tabular}

${ }^{*}$ sig $<0,05 \quad{ }^{* *} \operatorname{sig}<0,01$


correlacionada negativamente com a iniciativa e persistência. Isso significa que, ao existirem valores elevados numa dessas escalas, é de esperar que a outra apresente valores baixos.

\section{Discussão e conclusões}

Um primeiro aspecto a analisar dos dados obtidos prende-se com a vulnerabilidade/ não vulnerabilidade ao stress referida pelos professores. 0 cálculo da incidência de stress nos docentes da nossa amostra foi efectuado com base nas respostas dadas ao 23 QVS.

Assim, é de registar uma percentagem de professores que apresenta níveis curiosos de vulnerabilidade ao stress, 20,4\%, idênticos aos resultados encontrados num estudo português, realizado no Distrito de Beja que aponta percentagens de 23\% (Quirino, 2007). Esses valores diferem substancialmente dos índices de stress assinalados noutras investigações, confirmando-se assim a relevância do estudo desse tema.

Lembramos que, de acordo com Vaz Serra (2000), consideramos vulneráveis ao stress os indivíduos que, ao preencherem uma escala 23 QVS, obtiveram uma pontuação igual ou superior a 43 pontos. Como podemos constatar, no nosso estudo, os dados revelam apenas 20\% da população docente vulnerável ao stresse.

No entanto, o stress profissional dos docentes é um problema desde há muito reconhecido e estudado, pois a OIT (1981), no início da década de 80 do século XX, denunciava a gravidade da situação ao considerar a docência como uma profissão de risco de esgotamento físico e mental. Por outro lado, uma investigação levada a cabo por Pinto, Lima e Silva (2003), na zona da Direcção Regional de Educação de Lisboa, cujo instrumento de recolha de dados foi uma adaptação do Teacher Stress Questionnaire - TSQ de Kyriacou e Sutcliffe (1978), realça que 54\% dos professores da amostra percepcionam a docência como uma actividade muito ou extremamente geradora de stress.

Também Gomes et al. (2006), num estudo realizado com professores de uma escola Secun- dária do norte português, também registaram uma assinalável percentagem de docentes que considera sentir níveis significativos de pressão profissional, próximos dos 40\%, e referem ainda os valores encontrados noutros estudos portugueses que apontaram percentagens entre 45\% e 60\%. A compreensão dessas diferenças apela, naturalmente, para um olhar mais atento à intervenção de outros factores que as justifiquem na população docente portuguesa.

No que diz respeito à influência das variáveis sociodemográficas, o nosso estudo não apresenta diferenças significativas. Todavia, Gomes et al. (2008), num estudo realizado com enfermeiros que trabalham na zona norte, encontraram diferenças significativas em função dos factores pessoais.

Relativamente às variáveis profissionais, constatamos que 100\% dos vulneráveis ao stress são professores do $1^{\circ}$ Ciclo do Ensino Básico e licenciados, o que nos remete para estudos futuros no sentido do apuramento das razões que estão na génese dessa situação. Isso, obviamente, porque a amostra sugere que os docentes de outros níveis de ensino não são vulneráveis ao stress.

Numa análise às fontes de stress percepcionadas pelos professores, pudemos observar que o aspecto mais significativo dos resultados indica as dificuldades em lidarem com os comportamentos inadequados e com a indisciplina dos alunos (68\%), seguido das pressões de tempo e excesso de trabalho.

Depois, as diferentes capacidades e motivações dos alunos, as políticas disciplinares inadequadas e o estatuto da carreira docente são outras fontes de pressão bem representativas das experiências negativas vividas pelos professores.

Em relação ao estatuto da carreira docente, lembramos que, recentemente, já em 2008, foi aprovada nova legislação nessa matéria na Região Autónoma da Madeira, faltando ainda a respectiva regulamentação nalguns domínios, os quais poderão ter influência nos resultados obtidos.

0 trabalho burocrático administrativo foi também considerado importante, distanciandose, contudo, dos restantes resultados. 
Os resultados da nossa pesquisa confirmam parcialmente alguns estudos nacionais e internacionais que têm vindo a indicar que os comportamentos inadequados e a indisciplina dos alunos são percepcionados pelos professores como fontes de stress muito perturbadoras (Gomes et al. 2006; Pinto; Lima; Silva, 2003).

Segundo os dados obtidos neste estudo, as estratégias de coping mais utilizadas são as estratégias de controlo com $64,24 \%$, seguidas das estratégias de evitamento com 45,71\%. Menos frequente, mas também presente no leque de alternativas para lidar com o stress, é o recurso dos professores a estratégias de gestão de sintomas com 28,70\%.

Assim, no que concerne às estratégias de coping utilizadas pelos professores, os resultados compósitos do nosso estudo indicam que estes não recorrem apenas a estratégias tendencialmente adaptativas e funcionais nas tentativas que fazem para lidar com as dificuldades e exigências da profissão.

Resultados idênticos também foram obtidos nos estudos desenvolvidos por Jesus e Pereira (1994) e Quirino (2007). Nesse panorama, julgamos que, de uma forma geral, em situações de distress, os docentes optam preferencialmente por estratégias adaptadas, orientadas para a resolução do problema e baseadas em acções e reavaliações cognitivas proactivas (Jesus; Pereira, 1994).

No sentido de analisar se as estratégias de coping condicionam a presença de stress laboral, embora os resultados obtidos não tenham significado estatístico, pudemos aferir que os professores vulneráveis apresentam menos estratégias de controlo, mais estratégias de escape e de gestão de sintomas.

Nesse sentido, Latack (1986) considera que, no trabalho, os indivíduos que utilizam, sobretudo, estratégias de confronto produzem provavelmente melhores resultados. Logo, podemos depreender que os professores que, para lidarem com as dificuldades e exigências do trabalho optam por estratégias adaptativas e funcionais, orientadas para a resolução dos problemas, baseadas em acções e reavaliações cognitivas proactivas, apresentam menor vulnerabilidade ao stress.

Esse pressuposto está em consonância com os resultados do nosso estudo e com o explicitado por Latack (1986). No entanto, Jesus e Pereira (1994) previnem para o facto de não se poder considerar nenhuma estratégia de coping como a mais eficaz ou a mais adequada, sendo necessário considerar a situação em causa e os factores de personalidade e, ainda, o desenvolvimento de novos estudos no âmbito das estratégias de coping dos docentes.

Neste estudo, propusemo-nos ainda analisar se a autoeficácia condiciona a presença de stress laboral nos professores. Assim sendo, não podemos deixar de nos referir aos indicadores que tivemos a oportunidade de construir em relação à autoeficácia geral: 91,83\% na dimensão iniciativa e persistência e 96,05\% na eficácia perante a adversidade.

0 primeiro factor qualifica a apreciação que o indivíduo faz acerca da sua vontade para iniciar e para completar uma acção, e o segundo factor reporta-se à vontade de o indivíduo persistir numa actividade perante situações que são adversas até terminar essa acção (Ribeiro, 1995). Assim, na perspectiva de Bandura (1997), sendo a autoeficácia a avaliação da pessoa sobre a sua capacidade de cumprir com sucesso tarefas específicas, então, podemos deduzir que quanto maior for a sua percepção, maior probabilidade terá em realizar as suas actividades laborais. Isso significa que, se o indivíduo acredita nas suas habilidades de execução de uma tarefa específica, essa autoperceção concorrerá para aumentar a probabilidade dum desempenho eficaz (Salanova; Grau; Martínez, 2006; Ribeiro, 1995).

Também, na perspectiva de Jesus (2005), se uma situação profissional avaliada como difícil e exigente for bem-sucedida, trata-se de uma situação de eustress, pois o professor optimiza o seu funcionamento adaptativo de tal forma que, se no futuro for confrontado com uma situação idêntica, apresentar-se-á mais confiante e terá maior probabilidade de resolver o problema. Entretanto, pelo contrário, se o 
professor não for bem-sucedido e a tensão permanecer durante muito tempo, pode manifestar sintomas de distress que traduzem uma má adaptação à situação de exigência em que se encontra. Por isso, as expectativas de eficácia têm um papel muito importante no modo de cada pessoa enfrentar os desafios.

Nessa panorâmica, procuramos verificar se os níveis de autoeficácia são idênticos nos professores vulneráveis e não vulneráveis ao stress, ou seja, se esses dois tipos de professores reagem de igual modo. Nesse sentido, pudemos observar que existem diferenças significativas entre os professores vulneráveis e não vulneráveis ao stress no domínio da iniciativa e persistência, sendo que os primeiros apresentam pontuação média mais baixa.

Já no campo da eficácia perante a adversidade, os professores não vulneráveis apresentam níveis de eficácia superiores aos não vulneráveis. Contudo, essa diferença não tem significado estatístico, mas existe relação entre a vulnerabilidade ao stress e a autoeficácia. Em sentido geral, os resultados deste trabalho apoiam a ideia de Grau, Salanova e Peiró (2001) de que a autoeficácia harmoniza as relações entre o stress e as suas consequências.

0 nosso estudo permitiu relacionar o stress e a autoeficácia. Os resultados sugerem que, em sentido geral, a autoeficácia é uma variável muito importante no estudo do stress laboral, dado que está correlacionada com os modelos de apreciação cognitiva do stress (Lazarus; Folkman, 1984). Essas relações sugerem que os professores reagem negativamente quando percebem que não podem executar o seu trabalho de forma adequada e que altos níveis de autoeficácia podem significar uma valiosa estratégia para lidar com o stress.

Este estudo permitiu verificar que a percepção de maior eficácia perante a adversidade corresponde à utilização de mais estratégias de controlo para lidar com o stress. De facto, o controlo percebido reduz as expectativas de fracasso conforme outras pesquisas já demonstraram. Em contrapartida, o controlo percebido potencia a crença que as pessoas podem exercer controlo sobre o seu desempenho mesmo em situações complicadas e adversas (Grau; Salanova; Peiró, 2001).

Nesse âmbito, evidenciamos ainda o papel central do construto autoeficácia, pois é a sua percepção que vai favorecer ao professor o desenvolvimento de estratégias psicológicas capazes de modificar pensamentos e, consequentemente, comportamentos proactivos relacionados com o exercício docente.

Em sintese, podemos concluir que:

- Comparativamente aos estudos realizados em Portugal e no estrangeiro, a prevalência da vulnerabilidade ao stress, de acordo com a amostra, indicia ser significativamente menor na Região Autónoma da Madeira. Seria relevante que se realizassem novos estudos que pudessem abranger outros profissionais de serviços sociais, nomeadamente médicos, enfermeiros, assistentes sociais e/ou psicólogos, para dispormos de mais dados que ajudem na compreensão dos factores condicionantes do stress laboral e, consequentemente, da qualidade dos serviços prestados. Além disso, também seria importante analisar os factores que levam a que os professores do $1^{\circ}$ Ciclo do Ensino Básico sejam os que revelaram maiores índices de vulnerabilidade ao stress dentro da classe docente de acordo com este estudo preliminar.

- Os factores desencadeantes de stress nos professores estão, sobretudo, relacionados com comportamentos inadequados e indisciplina dos alunos, seguido das pressões de tempo e excesso de trabalho.

- Na verdade, as recorrentes contrariedades imprimidas ao professor associadas aos alunos são, como os nossos dados mostram, importantes fontes de stress para a classe em estudo, a quem interessa formar consistentemente nessas áreas de competências. Importa, por isso, a necessidade de o docente adquirir aptidões, que lhe permitam lidar eficazmente com as exigências profissionais geradoras de 
stress e, assim, promover a sua qualidade de vida laboral e a melhoria das suas práticas.

- As variáveis de coping mais utilizadas pelos professores são principalmente as estratégias de controlo. Em seguida, surgem as estratégias de escape e finalmente as de gestão de sintomas. De acordo com o nosso estudo, a vulnerabilidade ao stress é previsível em professores que não utilizam estratégias orientadas para a resolução de problemas e que recorrem a estratégias de escape e de gestão de sintomas. No entanto, preferimos adoptar prudência na interpretação das associações encontradas que nos remetem para a intervenção de outros processos e variáveis na explicação daquela síndroma.

- Este estudo denuncia, também, que os professores que utilizam estratégias de controlo são mais eficazes perante a adversidade. Nesse sentido, a autoeficácia pode ser considerada como preditora da vulnerabilidade ao stress, pois se a pessoa acredita que tem as competências necessárias, ela utiliza as estratégias de coping apropriadas para realizar as suas tarefas adequadamente.

- Finalmente, pesquisas que relacionem stress, coping e autoeficácia em conjunto não foram encontradas pelos autores em estudos portugueses, demonstrando que esses factores ainda precisam ser mais investigados. Além disso, devido à poderosa influência que esse construto exerce sobre as pessoas, o ideal seria criar desde a formação inicial um alto sentido de autoeficácia docente em todas as competências científicas e pedagógicas, tanto práticas como teóricas.

\section{Referências bibliográficas}

BANDURA, A. Self-efficacy: the exercise of control. New York: NY Freeman, 1997.

CAPEL, S. A longitudinal study of burnout in teachers. British Journal of Educational Psychology, v. 61, p. 36-45, 1991.

COCKBURN, A. Primary teachers knowledge and acquisition of stress relieving strategies. British Journal of Educational Psychology, v. 66, p. 339-410, 1996.

CRUZ, J.; FREITAS, M. Prevalência e fontes de stress nos professores: um estudo comparativo. In: International Conference on Counseling Psychology and Human Development. First. Actas... Porto, Portugal, jun., 1998.

CRUZ, J.; MESQUITA, A. Incidence and sources of stress in teaching. In: Conference of the Association for Teacher Education in Europe. 13th. Actas... Barcelona, Espanha, set., 1988.

FOLKMAN, S. et al. Dynamics of stressful encounter: cognitive appraisal, coping, and encounter outcomes. Journal of Personality and Social Psychology, v. 50, n. 5, p. 992-1003, 1986.

GARCÍA-RENEDO, M. et al. (2004). Antecedentes afectivos de la autoeficacia entre profesores: diferencias individuales. In SALANOVA, M. et al. (Eds.). Nuevos horizontes en la investigación sobre la autoeficacia. Castelló de la Plana: Publicacions de la Universitat Jaume I, D.L., 2004. p. 244-255.

GOMES, A. Questionário de stress nos professores. Braga: Universidade do Minho. 2007. Manuscrito não publicado.

GOMES, A. et al. Problemas e desafios no exercício da actividade docente: um estudo sobre o stress, 'burnout' saúde física e satisfação profissional em professores do 3. ${ }^{\circ}$ ciclo e ensino secundário. Revista Portuguesa de Educação, v. 19, n. 1, p. 67-93, 2006.

Stress, saúde física, satisfação e "burnout" em profissionais de saúde: análise das diferenças em função do sexo, estado civil e agregado familiar. In: PEREIRA, M. G.; SIMÃES, C.; MCINTYRE, T. (Eds.). In: Congresso, família, saúde e doença: modelos, investigação e prática em diferentes contextos de saúde. II. Actas..., 2. ed., IV, Braga: Universidade do Minho, p. 178-192, 2008.

GRAU, R.; SALANOVA, M.; PEIRÓ, J. Moderator effects of self-efficacy on occupational stres. Psychology in Spain, v. 5, n. 1, p. 63-74, 2001.

GUILLÉN GESTOSO, C. La importancia del estrés laboral en el mundo actual. Ateneo: revista cultural del Ateneo de Cádiz, v. 5, p. 84-95, 2005. 
HILL, M.; HILL, A. Investigação por questionário. Lisboa: Sílabo, 2008.

JESUS, S. Perspectivas para o bem-estar docente: uma lição de síntese. Porto: ASA. 2002.

Bem-estar docente: perspectivas para superar o mal-estar dos professores. In: PINTO, A. e SILVA, A. (Coords.). Stress e bem-estar. Lisboa: Climepsi, p. 17-42, 2005.

JESUS, S.; PEREIRA, A. Estudo das estratégias de "coping" utilizadas pelos professores. In: Seminário A Componente da Psicologia na Formaçã̃o e Outros Agentes Educativos. 5. Actas... Universidade de Évora, p. 253-268, 1994.

KYRIACOU, C.; SUTCLIFFE, J. Teacher stress: prevalence, sources and symptoms. British Journal of Educational Psychology, v. 48, p. 159-167, 1978.

LATACK, J. Career transitions within organizations: an exploratory study of work, nonwork and coping strategies. Organizational Behaviour and Human Performance, v. 34, p. 296-322, 1984.

Coping with job stress: measures and future directions for scale development. Journal of Applied Psychology, v. 71, n. 3, p. 377-385, 1986.

LAZARUS, R.; FOLKMAN, S. Stress, appraisal and coping. New York: Springer, 1984.

MOTA, C.; MATOS, P. Coping across situations questionnaire - CASQ numa amostra de adolescentes portugueses. Psychologica, v. 43, p. 211-226, 2006.

OIT. Emploi et conditions de travail des enseignants. Genova: Bureau International du Travail, 1981.

PINTO, A.; LIMA, M.; SILVA, A. Stress profissional em professores portugueses: incidência, preditores e reacção de burnout. Psychologica, v. 33, p. 181-194, 2003.

QUIRINO, A. Stress, coping e burnout em professores do $3^{\circ}$ Ciclo. 2007. Dissertação (Mestrado)- Universidade do Algarve, Portugal, 2007

RIBEIRO, J. Adaptação de uma escala de avaliação de autoeficácia geral. In: ALMEIDA, L. e RIBEIRO, I. (Eds.). Avaliação Psicológica: formas e contextos, Braga: APPORT, p. 163-176, 1995.

SALANOVA, M.; BRESÓ, E.; SCHAUFELI, W. Hacia un modelo espiral de las creencias de eficacia en el estúdio del burnout y del engagement. Ansiedad y Estrés, v. 11, n. 2-3, p. 215-231, 2005.

SALANOVA, M.; GRAU, M.; MARTínEZ, I. Job demands and coping behaviour: the moderating role of Professional self-efficacy. Psychology in Spain, v. 10, n. 1, p. 1-7, 2006.

SELYE, H. The stress of life. New York: McGraw-Hill, 1956.

SHERER, M. et al. The self-efficacy scale; construction and validation. Psychological Reports, v. 51, p. 663-671, 1982.

VAZ SERRA, A. 0 stress na vida de todos os dias. Coimbra: Edições do Autor, 1999.

A vulnerabilidade ao stress. Psiquiatria Clínica, v. 21, n. 4, p. 261-278, 2000.

As múltiplas facetas do stress. In: PINTO, A.; SILVA, A. (Coords.). Stress e bem-estar. Lisboa: Climepsi, 2005. p. 17-42.

TOFFLER, A. Choque do futuro. Lisboa: Edição Livros do Brasil, 1970.

Recebido em 11.11 .08

Aprovado em 05.05.09

Margarida Pocinho, doutorada em Educação, é professora auxiliar do departamento de Psicologia e Estudos Humanísticos da Universidade da Madeira, Portugal. E-mail: mpocinho@uma.pt

Maria Regina Capelo, doutoranda em Ciências do Trabalho na Universidade de Cadiz, Espanha, é delegada escolar na Secretaria Regional da Educação e Cultura, Madeira, Portugal. 